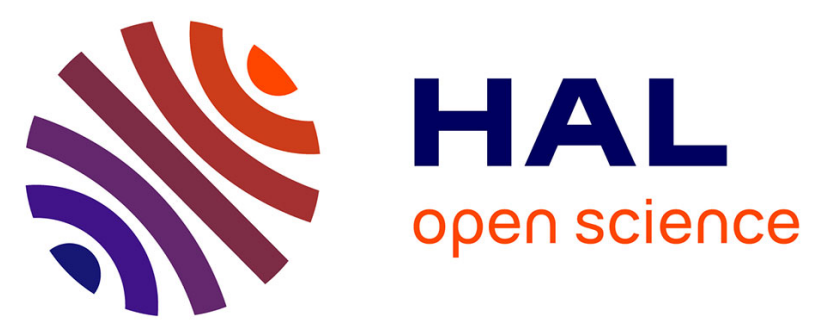

\title{
Evidence for a critical dose above which damage to carbonate ester bonds in PADC appear after gamma ray and ultra soft X-ray exposures
}

Tamon Kusumoto, Shogo Okada, Hisaya Kurashige, Kazuo Kobayashi, Michel Fromm, Quentin Raffy, Nicolas Ludwig, Masato Kanasaki, Keiji Oda, Yoshihide Honda, et al.

\section{To cite this version:}

Tamon Kusumoto, Shogo Okada, Hisaya Kurashige, Kazuo Kobayashi, Michel Fromm, et al.. Evidence for a critical dose above which damage to carbonate ester bonds in PADC appear after gamma ray and ultra soft X-ray exposures. Radiation Physics and Chemistry, 2020, 170, pp.108628. 10.1016/j.radphyschem.2019.108628 . hal-03557818

\section{HAL Id: hal-03557818 https://hal.science/hal-03557818}

Submitted on 4 Feb 2022

HAL is a multi-disciplinary open access archive for the deposit and dissemination of scientific research documents, whether they are published or not. The documents may come from teaching and research institutions in France or abroad, or from public or private research centers.
L'archive ouverte pluridisciplinaire HAL, est destinée au dépôt et à la diffusion de documents scientifiques de niveau recherche, publiés ou non, émanant des établissements d'enseignement et de recherche français ou étrangers, des laboratoires publics ou privés. 


\section{Journal Pre-proof}

Evidence for a critical dose above which damage to carbonate ester bonds in PADC appear after gamma ray and ultra soft X-ray exposures

Tamon Kusumoto, Shogo Okada, Hisaya Kurashige, Kazuo Kobayashi, Michel Fromm, Quentin Raffy, Nicolas Ludwig, Masato Kanasaki, Keiji Oda, Yoshihide Honda, Sachiko Tojo, Jean-Emmanuel Groetz, Ryo Ogawara, Satoshi Kodaira, Rémi Barillon, Tomoya Yamauchi

PII: S0969-806X(19)30762-5

DOI: https://doi.org/10.1016/j.radphyschem.2019.108628

Reference: $\quad$ RPC 108628

To appear in: Radiation Physics and Chemistry

Received Date: 3 July 2019

Revised Date: 25 November 2019

Accepted Date: 26 November 2019

Please cite this article as: Kusumoto, T., Okada, S., Kurashige, H., Kobayashi, K., Fromm, M., Raffy, Q., Ludwig, N., Kanasaki, M., Oda, K., Honda, Y., Tojo, S., Groetz, J.-E., Ogawara, R., Kodaira, S., Barillon, Ré., Yamauchi, T., Evidence for a critical dose above which damage to carbonate ester bonds in PADC appear after gamma ray and ultra soft X-ray exposures, Radiation Physics and Chemistry (2019), doi: https://doi.org/10.1016/j.radphyschem.2019.108628.

This is a PDF file of an article that has undergone enhancements after acceptance, such as the addition of a cover page and metadata, and formatting for readability, but it is not yet the definitive version of record. This version will undergo additional copyediting, typesetting and review before it is published in its final form, but we are providing this version to give early visibility of the article. Please note that, during the production process, errors may be discovered which could affect the content, and all legal disclaimers that apply to the journal pertain.

(c) 2019 Published by Elsevier Ltd. 
Author statement

TK, MF, JG, SK, RB, QR and NL carried our experiments (USX exposures) at Bourgogne-Franche-Comte. Also TK, KK, MK, TY, KO, YH and ST performed experiments (gamma exposures and ESR measurements) at Osaka University. TK spoke about data analysis with SO, HK, KK and TY. 


\title{
Evidence for a critical dose above which damage to carbonate ester bonds in PADC appear after gamma ray and ultra soft $X$-ray exposures
}

\author{
Tamon Kusumoto $^{\mathrm{a} *}$, Shogo Okada ${ }^{\mathrm{b}}$, Hisaya Kurashige ${ }^{\mathrm{c}}$, Kazuo Kobayashi ${ }^{\mathrm{d}}$, \\ Michel Fromm ${ }^{\mathrm{e}}$, Quentin Raffy ${ }^{\mathrm{f}}$, Nicolas Ludwig ${ }^{\mathrm{f}}$, \\ Masato Kanasaki ${ }^{\mathrm{g}}$, Keiji Oda ${ }^{\mathrm{g}}$, Yoshihide Honda ${ }^{\mathrm{d}}$, Sachiko Tojo ${ }^{\mathrm{d}}$, \\ Jean-Emmanuel Groetz ${ }^{\mathrm{e}}$, Ryo Ogawara ${ }^{\mathrm{a}}$, Satoshi Kodaira ${ }^{\mathrm{a}}$, \\ Rémi Barillon ${ }^{\mathrm{f}}$, Tomoya Yamauchi ${ }^{\mathrm{g}}$
}

${ }^{a}$ National Institutes for Quantum and Radiological Science and Technology, 4-9-1 Anagawa, Inage-ku, 263-8555 Chiba, Japan

${ }^{b}$ High Energy Accelerator Research Organization, KEK, 1-1 Oho, Tsukuba,305-0801 Ibaraki Japan

${ }^{c}$ Organization for Advanced and Integrated Research, Kobe University, 1-1 Rokkodai, Nada-ku,657-8501 Kobe Japan

${ }^{d}$ The Institute of Scientific and Industrial Research, Osaka University, 8-1 Mihogaoka, Ibaraki, 567-0047 Osaka, Japan

${ }^{e}$ UMR CNRS 6249 Chrono-Environnement, Université de Bourgogne-Franche-Comté, 16 Route de Gray, F-2530 Besançon Cedex, France

${ }^{f}$ Institut Pluridisiplinaire Hubert Curien, UMR 7178, CNRS, 23 rue du Loess, 67037 Strasbourg, France

${ }^{g}$ Graduate School of Maritime Sciences, Kobe University, 5-1-1 Fukaeminami-machi, Higashinada-ku, 658-0022 Kobe, Japan 


\begin{abstract}
It has been confirmed that the density of carbonate ester in poly(allyl diglycol carbonate) (PADC), which is a well-known polymeric nuclear track detector CR-39, begins decreasing above a critical dose of about $60 \mathrm{kGy}$ during exposures to Co-60 gamma rays and Ultra Soft X-rays (USX: $\mathrm{K} \alpha(\mathrm{Al})$ with energy $1.49 \mathrm{keV}$ ). After exposure to Co-60 gamma rays at $77 \mathrm{~K}$ and room temperature (RT), a significant difference in Electron Spin Resonance (ESR) spectra has been observed at both sides of a critical dose of $60 \mathrm{kGy}$, where is a threshold for the degradation of carbonate ester in PADC. Namely, the types of free radicals in PADC are different from each other below and above this critical dose. Changes in FT-IR spectra of carbonate ester in PADC above critical doses for gamma ray and USX exposures have also been observed, while that of ether decreases linearly with increasing absorbed dose. These results are well concordant with previous results obtained with $28 \mathrm{MeV}$ electron beams. They also indicate that at least two hits of electrons are needed to destroy the carbonate ester in PADC. The layered structure of ion tracks in PADC can be explained thanks to these experimental results. Also, some clues for the identification of created radicals have been obtained from the results using both ESR and IR.
\end{abstract}

Keywords : PADC, gamma ray, Ultra Soft X-ray, carbonate ester, ESR, FT-IR *Corresponding author

e-mail: kusumoto.tamon@qst.go.jp (Tamon Kusumoto) 


\section{Introduction}

Poly(allyl diglycol carbonate) (PADC), commonly known under the trade name CR-39, has been recognized as the most sensitive polymeric nuclear track detector (Cartwright et al., 1978). PADC can record tracks of protons (or neutrons from recoil protons) and heavy ions as etch pits without background noise from electrons, X-rays and gamma rays even in complex radiation mixed fields (Fukuda et al., 2009; Kanasaki et al., 2016). The fragmentation of ions, such as ${ }^{12} \mathrm{C}$ ions, can be followed using PADC thanks to its high charge resolution (Hirano et al., 2018). We have engaged in Fourier Transform Infrared (FT-IR) spectrometric studies on latent track structure of protons and heavy ions (from He to Xe ions) to elucidate an open question "why does PADC have such excellent features as a nuclear track detector?" from a point of view of molecular arrangements (Yamauchi, 2003; Mori et al., 2011\&2013; Kusumoto et al., 2015\&2016a). Other approaches for clarifying the structure and mechanism of latent tracks have been conducted (Kodaira et al., 2012; Fromm et al., 2019). The importance of the low-energy secondary electrons has been shown (Fromm et al., 2015; Kusumoto et al., 2018; Kai et al., 2018). Figure 1 illustrates a repeat unit of PADC, whose molecular formula is $\left(\mathrm{C}_{12} \mathrm{H}_{18} \mathrm{O}_{7}\right)_{\mathrm{n}}$ and density is $1.31 \mathrm{~g} / \mathrm{cm}^{3}$. PADC is constituted by the combination of a radiation-sensitive section and a less radiation-sensitive one. The former contains an ether moiety in the center and two carbonate esters in the symmetric positions, and the latter is "polyethylene-like" network formed during the polymerization. The structure of PADC is a three-dimensional network consisting of polyallyl chains (Stejny, 1987). Four methylene (two ethylene) groups belong to the radio-sensitive part of the structure lying between ether and carbonate ester moieties in each unit. Through FT-IR studies, we have estimated the effective track core radius for each functional group, in which the considered groups were damaged (Mori et al., 2011). Figure 2 shows the three different regions, where typical functional groups with specific vibration bands in PADC are damaged by $4.8 \mathrm{MeV} / \mathrm{u} \mathrm{C}$ ion irradiations, observed by FT-IR analysis. It appears that the radial extent of specific damages depends upon the type of chemical group analysis. In a first region, close to the ion's path, $\mathrm{CH}$ groups, carbonate ester and ether functions are affected. In a second, wider one, only carbonate ester and ether functions are affected. In the third, outer part, only ether function appears to be damaged. In these three regions of the latent track in PADC, mechanisms of damage formation by incoming ions are expected to be different from each other. Ether is clearly the most sensitive and carbonate ester is the second one. Similar spatial distribution of defects within the latent track were observed in some polymers such as poly(vinylidene fluoride) (Balanzat et al., 1995; Bouëdec et al., 1999) 
and polybisphenol A carbonate (Yamauchi et al., 2010).

In our recent study on the irradiation effect of PADC films with $28 \mathrm{MeV}$ electron beam, which was performed in ambient air, the relative density of ether decreased monotonically with absorbed doses (i.e., fluence) in the range from 0 to 200 kGy (Kusumoto et al., 2016b). In comparison to this, the carbonate ester was lost only above a critical dose of $50 \mathrm{kGy}$. The existence of a critical dose indicates a kind of threshold for the degradation of carbonate ester. Such a decreasing behavior was explained by a "two-electron model", in which the carbonate ester should be broken after the breaking of the ether in the same unit. Similar trends were observed with low-energy electrons up to $30 \mathrm{eV}$ and UV photon of a wavelength of $222 \mathrm{~nm}$ (Kusumoto et al., 2018\&2019a).

In the present study, we have investigated effects of irradiation on PADC due to exposures to gamma rays and X-rays, paying a special attention to a critical dose of about $50 \mathrm{kGy}$, above which carbonate ester begins to decrease. We examine the irradiation effects of PADC films with Co-60 gamma rays at absorbed doses up to 150 kGy, using FT-IR method, as well as Electron Spin Resonance (ESR) spectrometry. Some ESR studies were carried out for PADC after gamma irradiations (Khazal\&Habubi, 1990; Ranjbar et al., 1997), but only with much lower doses. Darraud-Taupiac et al., also made an ESR study of PADC with gamma rays, as well as ion beams, investigating a dose region ranging from 2 to $150 \mathrm{kGy}$ (Darraud-Taupiac et al., 1995). However, it was difficult to avoid the radical recombination during exposures due to the off-line measurements. Other ESR studies were also performed by Böhlke et al. using proton and $\mathrm{He}$ ion beams under vacuum (Böhlke et al., 2005; Böhlke\&Hermsdorf, 2008). Unfortunately, the radicals generated could not be identified in any of these studies. In the present one, ESR was applied to detect the free radicals induced in PADC films by gamma rays, avoiding most chemical reactions (e.g., radio-oxidation) by performing the experiments performed at $77 \mathrm{~K}$ using liquid nitrogen. Gamma ray exposures were also followed by ESR measurements at room temperature (RT). FT-IR studies for Ultra Soft X-ray (USX: photon energy $<2 \mathrm{keV}$ ) were also conducted to understand roles played by low-energy electrons compared to that produced by gamma ray.

\section{Experiments}

Thin PADC films were prepared by chemical etching in $\mathrm{KOH}$ solution $(6 \mathrm{M}$, $70 \square$ ) from BARYOTRAK sheets (Fukuvi Chemical Industry Co., Ltd., Japan) with a nominal thickness of $100 \mu \mathrm{m}$, which were made from monomer of purity higher than 
99\% (Yamauchi et al., 1999). Detailed thinning process is described elsewhere (Yamauchi et al., 2008). We used thin PADC films with thicknesses of less than $3 \mu \mathrm{m}$ to obtain unsaturated IR spectra (absorbance $<2$ ), including carbonate ester, which has the strongest IR absorption, as indicated in panels from (c) to (f) of Fig. 3. Additionally, films of a thickness of about $20 \mu \mathrm{m}$ were used to efficiently detect free radicals formed during gamma ray exposures.

Gamma ray exposures were carried out in ambient air at $77 \mathrm{~K}$ (using liquid nitrogen) and RT using the intense Co-60 source "Rabbit 11", an equipment of The Institute of Scientific and Industrial Research, Osaka University, Japan. The source activity was $147.1 \mathrm{TBq}$ on October 1st, 2017. The examined absorbed dose ranged from 30 to $150 \mathrm{kGy}$, with a constant rate of $1.6 \mathrm{~Gy} / \mathrm{s}$. During gamma ray exposures, PMMA sheets of a thickness of $2 \mathrm{~mm}$ were installed in front of PADC films to achieve the electron equilibrium condition. We also performed USX exposures in ambient air at RT at the Laboratoire Chrono-Environnment (UMR CNRS 6249) of the Université de Bourgogne-Franche-Comté, France. The USX from Ka line of Al (1.49 keV) was used in the present study. The beam profile was guaranteed to be uniform on at least a diameter of $3 \mathrm{~mm}$ (Ounoughi et al., 2013). The mean absorbed dose rate in PADC films was $1.0 \mathrm{~Gy} / \mathrm{s}$. The examined dose range was up to $180 \mathrm{kGy}$. The derivation process of the mean absorbed dose rate in a medium is presented elsewhere (Fullford et al., 1999; Groetz et al., 2014). In the energy region of USX, the photoelectric effect is the main interaction. The molecular chains of PADC mainly consist of $\mathrm{C}$ atoms. The peak of binding energy of $\mathrm{C} \mathrm{K}$-shell to the atom is $0.28 \mathrm{keV}$. Thus, as an approximation, we calculated the stopping power of photoelectrons $(1.21 \mathrm{keV})$ to be $13.3 \mathrm{eV} / \mathrm{nm}$ using the stopping power and range tables for electron, ESTAR (Berger et al., 2005).

To detect free radicals after gamma exposures, Electron Spin Resonance, ESR, spectroscopy was carried out at both $77 \mathrm{~K}$ and RT using JES-RE2X (JEOL, Japan) (Resolution: $2 \mu \mathrm{T}$, Range of magnetic field: $275 \sim 375 \mathrm{mT}$ ). Since the chemical reactions at $77 \mathrm{~K}$ after the gamma ray exposures proceed much slower than at RT, we could detect other radicals, which are likely to be less stable than that at RT, although they were not necessary the initial ones. For examining created chemical damages in PADC after gamma ray exposures, FT-IR measurements were also carried out before and after the exposures with spot of $1 \mathrm{~cm}$ in diameter using FT/IR-6100S (JASCO, Japan) equipped with a DTGS detector (Resolution: $2 \mathrm{~cm}^{-1}$, Range of wavenumber: 500 2000 $\mathrm{cm}^{-1}$, Repetitions: 50). In addition, microscopic FT-IR measurements using IRT-5000 (JASCO, Japan), equipped with a MCT detector, with a spot area of $50 \times 50 \mu \mathrm{m}^{2}$ were conducted (Resolution: $2 \mathrm{~cm}^{-1}$, Range of wavenumber: 500 2000 $\mathrm{cm}^{-1}$, Repetitions: 50). 
The uniform intensity of USX was guaranteed with spot of $6 \mathrm{~mm}$ in diameter, which is smaller than that of FT/IR-6100S. Therefore, we adapted the IRT-5000 for investigating created damages in PADC after exposures to USX. In the present study, we focused on the peaks of ether, carbonate ester at 1250 and $1770 \mathrm{~cm}^{-1}$ for carbonyl $(\mathrm{C}=\mathrm{O})$ and C-O-C, respectively, and $\mathrm{CH}$ groups at $789 \mathrm{~cm}^{-1}$ as shown in Fig. 3 (Lounis-Mokrani et al., 2003). Concerning ether, we can find three peaks from 1000 to $1200 \mathrm{~cm}^{-1}$. In the present study, the peak at $1026 \mathrm{~cm}^{-1}$, which is isolated compared to the others, was chosen for the analysis.

\section{Results and Discussions}

The track registration sensitivity of PADC has been considered to be related to the oxygen concentration in ambient air rather than in water and under nitrogen (Ishigure et al., 1989). In practice, the track registration sensitivity of PADC significantly drops under vacuum (Yamauchi et al., 1992; Dörschel et al., 2005). However, focusing on the latent track structure, which is strongly related to the track registration sensitivity, radiation chemical yields ( $G$ value) for losses of carbonate ester in PADC irradiated with $\mathrm{He}$ and $\mathrm{C}$ ions under vacuum are well agreement with those in ambient air (Mori et al., 2013). Aside from this, the creation of $\mathrm{OH}$ groups as new end-chain points after the irradiation under vacuum is dramatically smaller than that in ambient air (Kusumoto et al., 2019b). Namely, the track registration sensitivity could be governed by the amount of $\mathrm{OH}$ groups after the irradiations, which are created by radio-oxidation effects (Fujii et al., 1987; Böhlke\&Hermsdorf, 2008). Therefore, ESR spectrometry is carried at $77 \mathrm{~K}$ and RT to elucidate the chemical reaction of created radicals with oxygen. We observe clearly different ESR signals measured after exposures to Co-60 gamma rays at $77 \mathrm{~K}$ compared to that at RT. Additionally, the ESR signals depend on absorbed dose (details are discussed in section 3.1.), so that we carefully examine the reduction behavior of the relative density of the radiation-sensitive moieties in PADC (described in section 3.2).

\subsection{ESR measurements}

Figure 4 shows ESR spectra of PADC exposed to Co-60 gamma rays with absorbed doses of 33 (full red line), 67 (dotted black line) and $100 \mathrm{kGy}$ (chain green line). Both gamma ray exposures and ESR measurements were performed at $77 \mathrm{~K}$. In this case, we can observe signals at 300 and $350 \mathrm{mT}$. These signals are not observed when exposures and ESR measurements were done at RT (Figure 5). Indeed, typical 
ESR spectra of hyperfine structure of hydrogen radicals were observed around 300 and $350 \mathrm{mT}$ by other researchers (e.g., Kiselev et al., 2003; Nakashima\&Yamauchi, 2005; Stößer\&Herrmann, 2013). Note that experimental conditions of previous studies were different from the present study (e.g., measurement temperature and polymer used). However, signals assigned to hydrogen radicals were observed at 77 and $100 \mathrm{~K}$ (Sevilla et al., 1997). Thus, we may guess that the signals at 300 and $350 \mathrm{mT}$ are assigned to hydrogen radicals. Generated hydrogen radicals react with themselves or other radicals and then hydrogen gas can be released. Hydrogen radicals are known to have high reaction rates in aqueous organic materials (typically $10^{4}-10^{9} \mathrm{~mol} / \mathrm{s}$ ) (Neta and Schuler, 1971) and are in consequence characterized by very short lifetimes. In solid state polymers, lifetimes are thus even shorter. In comparison to this, it is well known that hydrogen gas is easily released from the polymer after bombardment (Rowntree et al., 1991; Ferry et al., 2016; Kusumoto et al., 2019b), so signals at 300 and $350 \mathrm{mT}$ are not observable at RT.

The clear signals (labeled "a" and "b") are observed already after an exposure at $33 \mathrm{kGy}$. At $67 \mathrm{kGy}$, new signals (labeled "d" and "e") are seen near to $326.5 \mathrm{mT}$. Additionally, the signal labeled " $b$ " is shifted to a lower magnetic field. This implies that at higher accumulated dose, one can observe the formation of a new radical. Based on the previously proposed two-electron model, we can postulate that the new signals can be assigned to the radicals induced by damage to the carbonate ester. A similar spectrum is seen for $100 \mathrm{kGy}$. However, the peak height at $100 \mathrm{kGy}$ is lower than at 67 $\mathrm{kGy}$. This might indicate the saturation of damage to ether. Generally, oxygen radicals exhibit anisotropy signals (Swarts et al., 1989), in that way the observed signals might be assigned to radicals centered on carbon atoms in PADC. Unfortunately, we have no further evidence for the identification of the observed radicals presently.

The ESR spectra measured at RT are more complex than those at $77 \mathrm{~K}$ (Figure 5). It is well known that free radicals induced on ether and/or carbonate ester groups immediately re-arrange at RT (Faucitano et al., 1992; Shiryaeva et al., 2016). The carbon radicals are easily oxidized into peroxyl radicals (Jahan and Durant, 2005; Csige, 1997), which recombine faster than the carbon radicals. Such recombination processes must be considered to clarify the kinetics of further chemical etching. As it will be observed just after, below a critical dose, we have observed the reduction of the density of ether in PADC, while those of carbonate ester and $\mathrm{CH}$ groups are almost constant. This trend indicates that ether is the weakest moiety in PADC network. In our previous work (Kusumoto et al., 2015), we have demonstrated that ratio of $\mathrm{OH}$ groups formed/ether lost was between 1 and 2. This finding implied that one damage to ether 
produced formation of one or two $\mathrm{OH}$ group. The formation process of $\mathrm{OH}$ groups is in competition with recombination processes in the original structure or in the altered structure. These reactions spread along ion trajectory (i.e., secondary electron trajectories). Consequently, it is now considered that $\mathrm{OH}$ groups are created at new chain-end points. To clarify the difference between etchable tracks and un-etchable ones, the role of $\mathrm{OH}$ groups, which is hydrophilic and governs etching velocity along ion tracks, is crucial.

In the present study, the radical species at both $77 \mathrm{~K}$ and $\mathrm{RT}$ could not be identified. However, notable differences in ESR spectra above and below the critical dose are observed at both temperatures, so that FT-IR studies are carried out to examine the chemical damage structure at both sides of the critical dose (section 3.2). In addition, the difference in ESR spectra between $77 \mathrm{~K}$ and RT seems to indicate the influence of oxygen in ambient air. The radical annihilation process should be traced by annealing to clarify the role of oxygen in ambient air in a further step.

\subsection{FT-IR measurements}

After the exposure to Co-60 gamma rays, the changes in absorbance at each peak are observed (Figure 3). After the exposure with absorbed dose of $60 \mathrm{kGy}$, the peak height of net absorbance of ether slightly decreases as shown in Fig. 3 (a). Conversely, the other peaks of carbonate ester $(\mathrm{C}-\mathrm{O}-\mathrm{C}$ and $\mathrm{C}=\mathrm{O})$ and $\mathrm{CH}$ groups as represented in Fig. 3 (c), (e) and (g) do not decrease. In comparison to these spectra at $60 \mathrm{kGy}$, clear decreases are seen in the all peaks after the exposure with $300 \mathrm{kGy}$ (Mori et al., 2009). Similar trends were observed in the cases of $28 \mathrm{MeV}$ electron and UV photons (Kusumoto et al., 2016(a)\&2019(a)). We call such trends "two-step damage formation process" as discussed later.

The Beer-Lambert law has been usually applied to analysis of degradation process on polymer irradiated with ionizing radiations as,

$A_{0}=\varepsilon c_{0} l$,

where $A_{0}$ is absorbance before irradiation, $\varepsilon$ the molar extinction coefficient (in $\mathrm{M}^{-1} \mathrm{~cm}^{-1}$, $c_{0}$ molar density (in $\mathrm{M}=\mathrm{mol} / \mathrm{L}$ ) before irradiation and $l$ sample thickness (in $\mathrm{cm}$ ). Generally, the changes in absorbance are correspond to those in the density of functional groups because the molar extinction coefficient and the sample thickness can be considered as constant before and after exposures. Figure 6 (a) and (b) show the decrease of relative absorbance; $A / A_{0}$ the ratio of the net absorbance of considered functional groups after the exposure, $A$, to that of original one, $A_{0}$, of typical functional groups in PADC exposed to gamma ray and USX, respectively. Here, exposures were 
performed at RT in ambient air. As discussed above, the reductions of relative absorbance are proportional to those of relative density; $N / N_{0}$ the ratio of the density of considered functional groups after the exposure, $N$ (in mol $/ \mathrm{kg}$ ), to that of original one, $N_{0}$. Concerning obtained results of Co-60 gamma ray, the relative absorbance of ether drops linearly with absorbed dose. This trend implies that the overlapping effect by electron tracks is negligible (Kusumoto et al., 2019b). Conversely, the relative absorbance of carbonyl, which composes carbonate ester, does not decrease below a critical dose of $60 \mathrm{kGy}$. Seeing the present results together with previous one (open symbols of inset of Fig. 6 (a)) (Mori et al., 2009), a monotonic decrease of the relative absorbance of $\mathrm{C}=\mathrm{O}$ is observable above that critical dose. The reduction behavior of C-O-C, which also composes carbonate ester, is almost identical to that of carbonyl. The critical dose for damage to $\mathrm{CH}$ groups is clearly higher than that of carbonate ester under gamma ray exposure. Furthermore, the relative absorbance of ether decreases slowly above $110 \mathrm{kGy}$ due to the induced modification in PADC. A similar trend is seen on USX exposures (Figure 6 (b)). In the case of USX, the critical dose of carbonate ester loss is $50 \mathrm{kGy}$ and the reduction behavior of ether becomes slower above $75 \mathrm{kGy}$. The two-step damage formation process implies that the carbonate ester is often broken after damage to ether in the same molecule (Kusumoto et al., 2018). Ethylene like molecules are released when carbonate ester is damaged (Yamauchi et al., 2005). Hence, we can suggest that detected free radicals at $33 \mathrm{kGy}$ (see Fig. 4) could be due to damages to ether. Those observed at 67 and $100 \mathrm{kGy}$ would then be created by the breaking of carbonate ester.

A similar dependence on the absorbed dose was observed with $28 \mathrm{MeV}$ electrons irradiation of PADC (Kusumoto et al., 2016a). This phenomenon was interpreted as the overlapping of electron tracks, with a critical dose of $50 \mathrm{kGy}$, which is well in agreement with the present gamma ray and USX experiments, within experimental error. Due to the random motions of low energy electrons, we cannot apply the conventional track overlapping model using random numbers in the present cases of gamma ray and USX (Yamauchi, 2003). However, it is certain that the two-step damage formation process is related to changes in the damage creation mechanism to PADC above the critical dose discussed in the section 3.1.

The decrease of relative absorbance of ether can be described as, $A / A_{0}=1-k D$.

where $D$ is the absorbed dose in units of Gy and $|k|\left((8.9 \pm 0.3) \times 10^{-7}\right.$ for Co-60 gamma rays and $(12.8 \pm 0.5) \times 10^{-7}$ for USX) an experimental constant in units of $\mathrm{Gy}^{-1}$, which is 
concordant with the slope of the fitted lines in Figs. 6 (a) and (b). Using $k$, we can easily calculate the $\mathrm{G}$ value (in scissions $/ 100 \mathrm{eV}$ ) as,

$G$ value $=9.64 \times 10^{6} N_{0} k$,

where $N_{0}$ is $3.65 \mathrm{~mol} / \mathrm{kg}$ for ether and $7.3 \mathrm{~mol} / \mathrm{kg}$ for carbonate ester (Mori et al., 2009). The molecular weight of PADC, $M$, is equal to $274 \mathrm{~g} / \mathrm{mol}$, namely the reciprocal is 3.65 $\mathrm{mol} / \mathrm{kg}$. As in one PADC unit, there is one ether, so that $N_{0}$ is for this function is equal to $3.65 \mathrm{~mol} / \mathrm{kg}$. Similarly, as one PADC unit contains two carbonate ester moieties, accordingly, $N_{O}$ value for this function is twice that of PADC (i.e., $7.3 \mathrm{~mol} / \mathrm{kg}$ ). Figure 7 represents the $\mathrm{G}$ values for loss of ether ( $\mathrm{G}$ (ether losses)) as a function of the stopping power. Overall, surprisingly high $\mathrm{G}$ values (> 10 scissions/100 eV) have been observed in the case of PADC. In the past, Yamauchi et al., verified derivation processes (e.g., analysis procedures, irradiations and so on) of effective track core radius, which can be derived from same analysis with the $G$ value, using bisphenol a polycarbonate (Yamauchi et al., 2010). The results were well agreement with the others using FT-IR (Dehaye et al., 2003; Sun et al., 2003a\&2003b) and other approaches (Petersen\&Enge, 1995; Apel et al., 1999). Also, regarding the effective track core radii derived using FT-IR method by Mori et al., (Mori et al., 2011), they corresponded to the ones evaluated by conductimetric method (Oganesyan et al., 2005), AFM and UV-visible methods (Yamauchi et al., 2005b). In other words, the high $\mathrm{G}$ values obtained in the present study express the great radiation-sensitivity of PADC already observed. The solid squares on Fig. 7 indicate the present result related to Co-60 gamma ray. In the present case, abscissa coordinates for gamma rays and $28 \mathrm{MeV}$ electrons are respectively represented as average $L E T$ in water of gamma rays $(0.2 \mathrm{eV} / \mathrm{nm})$ and the deposited energy per unit distance of $28 \mathrm{MeV}$ electrons in water $(0.03 \mathrm{eV} / \mathrm{nm})$. The latter was approximated under non-electron equilibrium condition using well calibrated cellulose triacetate (CTA) dosimeter and electric current (Oda et al., 1997). The definitions of the stopping power and LET are different. LET is local energy deposition only, so that it does not include Bremsstrahlung or delta-rays. In comparison to this, the stopping power is the total energy deposition by incoming particles. However, we compare $\mathrm{G}$ values to elucidate both of the discrete damages along electron tracks and dense damages along proton and heavy ion tracks. The previously obtained $G$ value with gamma rays is smaller than the present one. In the previous study, the G value for ether loss was underestimated because data sets above $100 \mathrm{kGy}$, where chemical structure of PADC was completely modified, were used (Mori et al., 2009). On one hand, the G value obtained with USX is greater than that of gamma rays. This may imply that the lower energy of secondary electrons produces more efficiently 
irreversible damages in PADC. On the other hand, the $\mathrm{G}$ values related to gamma ray and USX exposure are greater than those of protons, He and $\mathrm{C}$ ions with energies in the Bragg peak regime (open circles in Fig. 7). By contrast, higher $\mathrm{G}$ values are observed for high energy protons and semi-relativistic heavy ions ( $\mathrm{C}$ and $\mathrm{Fe}$ ), as shown in open diamonds in Fig. 7 (Mori et al., 2012; Kusumoto et al., 2016a). The higher G values indicate that the PADC molecular network is efficiently damaged by dense-secondary electrons along heavy ion tracks, and is mainly modified not only in the close vicinity of the ion trajectory, but also at distant locations (Mori et al., 2012). For example, in the case of $10 \mathrm{MeV}$ protons, low-energy secondary electrons (e.g. $<40 \mathrm{eV}$ ) represent the major components in the energy spectrum (Fromm et al., 2015). The inelastic mean free path of electrons has a minimum value at an energy of about $40 \mathrm{eV}$ (Seah\&Dench, 1979). Then, it increases with energy. Secondary electrons with higher energies (> 40 $\mathrm{eV}$ ), which are rare components, mainly could interact with PADC at distant location from the ion's path. Therefore, we should consider the energy distribution of secondary electrons at each location to more accurately discuss the damage formation mechanism in PADC.

Eq. (1) is inapplicable to the carbonate ester and $\mathrm{CH}$ groups in PADC exposed to gamma ray in the normal manner, because monotonic decrease of the relative absorbance can be observed only above the critical dose (Fig. 6). Since the relative absorbance of carbonate ester is constant below the critical dose, the $\mathrm{G}$ values of gamma ray and USX should be extremely small below the critical dose. Above the critical dose, the $G$ values with gamma ray and USX were evaluated from the slope of fitted lines in Fig. 6 for carbonate ester. The $\mathrm{G}$ values for loss of carbonyl ( $\mathrm{G}$ (carbonate ester losses) are summarized in Fig. 8. As with Fig. 7, the present result of gamma ray is plotted as solid square and previous ones are described as open triangles, as well as $28 \mathrm{MeV}$ electrons. The $\mathrm{G}$ values of gamma ray and USX drastically rises above the critical doses (Figure 8). Noteworthy, the trend of C-O-C is identical to that of carbonyl (Figure 8). In the case of carbonate ester, it is difficult to compare the $\mathrm{G}$ values of Co-60 gamma rays and USX to those of proton and heavy ions because the overlapping of electron tracks is not negligible above the critical dose. But it is sure that radiation-sensitivity of carbonate ester becomes high when the ether in the same molecule is broken. In other words, more than two electrons are mandatory to break carbonate ester in PADC.

The present results obtained using ESR and FT-IR spectrometric methods strongly show that the concept of the number of electrons (and their energies), which interact with a molecule, may represent an appropriate parameter to the damage formation process of PADC. We will tackle the calculation of number of electrons, 
which hit molecules, at critical doses of Co-60 gamma rays and USX using MPEXS-DNA, a GPU-based Monte Carlo simulation (Okada et al., 2019) and an improved computer code of Geant4-DNA (Agostinelli et al., 2003; Allison et al., 2013\&2016), and PHITS code (Sato et al., 2018). The number of electrons from Co-60 gamma rays and USX will be compared to that experimentally obtained with an energy of $28 \mathrm{MeV}$.

\section{Conclusions}

In the present study, the creation mechanism of latent tracks in PADC, which was exposed to gamma rays and USX, was investigated by means of ESR and FT-IR spectrometry. For gamma rays at RT and $77 \mathrm{~K}$, different ESR spectra were observed below and above the critical dose. The present study did not achieve the identification of free radicals formed during gamma ray exposures. Nevertheless, the results suggest that damage formation mechanism is dose-dependent. While the relative absorbance (IR signal) for loss of ether decreased linearly with increasing absorbed dose, those of carbonate ester and $\mathrm{CH}$ groups decreased only above critical doses of $60 \mathrm{kGy}$ and 50 kGy for gamma rays and USX, respectively, which are in agreement with that found when using $28 \mathrm{MeV}$ electrons. The dose-dependent damage formation process was verified from both approaches. Based on our previously proposed two-electron model, we summarize that more than two electrons are necessary to induce damage to carbonate ester in PADC and number of electrons interacting with molecules is a suitable parameter to describe the damage formation process in PADC.

\section{Acknowledgments}

This work was performed by the Cooperative Research Program of "Network Joint Research Center for Material and Devices", and was supported by JSPS KAKENHI Grant Number 16K05002. This work was conducted thanks to the funds of Kobe University for the Cotutelle program with Universite de Strasbourg. The authors gratefully thank to Mr. Takuya Otani for his large supports during the experiments and express our appreciation to all the staff of The Institute of Scientific and Industrial Research of Osaka University for their cooperation in this experiment.

\section{References}

Agostinelli, S., Allison, J., Amako, K., Apostolakis, J., Araujo, H., Arce, P., Asai, M., 
Axen, D., Banerjee, S., Barrand, G., Behner, F., Bellagamba, L., Boudreau, J., Broglia, L., Brunengo, A., Burkhardt, H., Chauvie, S., Chuma, J., Chytracek, R., Cooperman, G., Cosmo, G., Degtyarenko, P., Dell'Acqua, A., Depaola, G., Dietrich, D., Enami, R., Feliciello, A., Ferguson, C., Fesefeldt, H., Folger, G., Foppiano, F., Forti, A., Garelli, S., Giani, S., Giannitrapani, R., Gibin, G., Gómez Cadenas, G.G., González, I., Gracia Abril, G., Greeniaus, G., Greiner, W., Grichine, V., Grossheim, A., Guatelli, S., Gumplinger, P., Hamatsu, R., Hashimoto, K., Hasui, H., Heikkinen, A., Howard, A., Ivanchenko, V., Johnson, A., Jones, F.W., Kallenbach, J., Kanaya, N., Kawabata, M., Kawabata, Y., Kawaguti, M., Kelner, S., Kent, P., Kimura, A., Kodama, T., Kokoulin, R., Kossov, M., Kurashige, H., Lamanna, E., Lampén, T., Lara, V., Lefebure, V., Lei, F., Liendl, M., Lockman, W., Longo, F., Magni, S., Maire, M., Medernach, E., Minamimoto, K., Mora de Freitas, P., Morita, Y., Murakami, K., Nagamatu, M., Nartallo, R., Nieminen, P., Nishimura, T., Ohtsubo, K., Okamura, M., O’Neale, S., Oohata, Y., Paech, K., Perl, J., Pfeiffer, A., Pia, M.G., Ranjard, F., Rybin, A., Sadilov, S., Di Salvo, E., Santin, G., Sasaki, T., Savvas, N., Sawada, Y., Scherer, S., Sei, S., Sirotenko, V., Smith, D., Starkov, N., Soecker, H., Sulkimo, J., Takahata, M., Tanaka, S., Tcherniaev, E., Safai Tehrani, E., Tropeano, M., Truscott, P., Uno, H., Urban, L., Urban, P., Verderi, M., Walkden, A., Wander, W., Weber, H., Wellisch, J.P., Wenaus, T., Williams, D.C., Wright, D., Yamada, T., Yoshida, J., Zschieche, D., 2003, GEANT4 - A simulation toolkit, Nucl. Instrum. Meth. A 506, 250-303.

Allison, J., Amako, K., Apostolakis, J., Araujo, H., Arce Dubois, P., Asai, M., Barrand, G., Capra, R., Chauvie, S., Chytracek, R., Cirrone, G.A.P., Cooperman, G., Cosmo, G., Cuttone, G., Daquino, G.G., Donszelmann, M., Dressel, M., Folger, G., Foppiano, F., Generowicz, J., Grichine, V., Guatelli, S., Gumplinger, P., Heikkinen,A., Hrivnacova, I., Howard, A., Incerti, S., Ivanchenko, V., Johonson, T., Jones, F., Koi, T., Kokoulin, R., Kossov, M., Kurashige, H., Lara, V., Larsson, S., Lei, F., Link, Longo, F., Maire, M., Mantero, A., Mascialino, B., McLaren, I., Mendez Lorenzo, P., Minamimoto, K., Murakami, K., Nieminen, P., Pandola, L., Parlati, S., Peralta, L., Perl, J., Pfeiffer, A., Pia, M.G., Ribon, A., Rodrigues, P., Russo, G., Sadilov, S., Santin, G., Sasaki, T., Smith, D., Starkov, N., Tanaka, S., Tcherniaev, E., Tome, B., Trindade, A., Truscott, P., Urban, L., Verderi, M ., Walkden, A., Wellisch, J.P., Williams, D.C., Wright, D., Yoshida, H., 2013. IEEE Trans on Nuclear Science 53, 270-278.

Allison, J., Amako, K., Apostolakis, J., Arce, P., Asai, M., Aso, T., Bagli, E., Bagulya, A., Banerjee, S., Barrand, G., Beck, B.R., Bogdanov, A.G., Brandt, D., Brown, J.M.C., 
Burkhardt, H., Canal, Ph., Cano-Ott, D., Chauvie, S., Cho, K., Cirrone, G.A.P., Cooperman, G., Cortés-Giraldo, M., Cosmo, G., Cuttoe, G., Depaola, G., Desorgher, L., Dong, X., Dotti, A., Elvira, V.D., Folger, G., Francis, Z., Galoya, A., Garnier, L., Gayer, M., Genser, K.L., Grichine, V.M., Guatelli, S., Guèye, P., Gumplinger, P., Howard, A.S., Hřivnáčová, I., Hwang, S., Incerti, S., Ivanchenko, A., Ivanchenko, V.N., Jones, F.W., Jun, S.Y., Kaitaniemi, P., Karakatsanis, N., Karamitros, M., Kelsey, M., Kimura, A., Koi, T., Kurashige, H., Lechner, A., Lee, S.B., Longo, F., Maire, M., Mancusi, D., Mantero, A., Mendoza, E., Morgan, B., Murakami, K., Nikitina, T., Pandola, L., Paprocki, P., Perl, J., Petrović, I., Pia, M.G., Pokorski, W., Russo, G., Satin, G., Sasaki, T., Sawkey, D., Shin, J.I., Strakovsky, I.I., Taborda, A., Tanaka, S., Tomé, B., Toshito, T., Tran, H.N., Truscott, P.R., Urban, L., Uzhinsky, V., Verbeke, J.M., Verderi, M., Wendt, B.L., Wenzei, H., Wright, D.H., Yamashita, T., Yarba, J., Yoshida, H., 2016. Recent developments in Geant4, Nucl. Instrum. Meth. B. 28, 49-52.

Apel, P., Sphor, R., Trautmann, C., Vutsadakis, 1999. Track structure in polyethylene terephthalate irradiated by heavy ions: LET dependence of track diameter. Radiat. Meas. $31,51-56$.

Balanzat, E., Betz, N., Bouffard, S., 1995. Swift heavy ion modification of polymers. Nucl Instrum. Meth. B 105 46-54.

Berger, M., Coursey, J., Zucker, M., Chan, J., 2005. ESTAR, PSTAR, and ASTAR: Computer programs for calculating stopping-power and range tables for electrons, protons, and helium ions, Version 1.2.3. [Online] Available: http://physics.nist.gov/Star. National Institute of Standards and Technology, Gaithersburg, MD.

Böhlke, S., Hermsdorf, D., 2008. Correlation of track etching properties of SSNTDs with the density of free radicals produced by charged particles in PADC, Radiat. Meas. $43,65-75$.

Böhlke, S., Hermsdorf, D., Sichelschmidt, J., Starke, S., 2005. Investigation of free radicals induced by light ions in CR-39 using ESR spectroscopy. Radiat. Meas. 40, 218-223.

Bouëdec, A.Le., Betz, N., Esnouf, S., Moël, A.Le., 1999. Swift heavy ion irradiation effects in $\alpha$ poly(vinylidene fluoride): spatial distribution of defects within the latent 
track. Nucl. Instrum. Meth. B 151, 89-96.

Cartwright, B.G., Shirk, E.K., Price, P.B., 1978. A nuclear-track-recording polymer of unique sensitivity and resolution. Nucl. Instrum. Meth. B 41, 447-460.

Csige, U., 1997. Post-irradiation sensitization of CR-39 track detector in carbon dioxide atmosphere. Radiat. Meas. 28, 171-178.

Darraud-Taupiac, C., Decossas, J.-L., Vareille, J.-C., Stejny, J., 1995. Study of free radicals in poly(diethylene glycol bis(allyl carbonate)) irradiated by $\gamma$ rays. Polymer 36 , 3251-3254.

Dehaye, F., Balanzat, E., Ferain, E., Legras, R., 2003. Chemical modifications induced in bisphenol A polycarbonate by swift heavy ions. Nucl. Instrum. Meth. B 209, 103-112.

Dörschel, B., Hermsdorf, D., Starke, S., 2005. Influence of oxygen on the track etch rate along light ion trajectories in CR-39. Radiat. Meas. 40, 234-239.

Faucitano, A., Buttafaya, A., Martinotti, F., Ferloni, P., Magistris, A., 1992. The mechanism of gamma-radiolysis of polymethylene, polypropylene and poly-n-butylene oxides: An ESR investigation. Radiat. Phy. Chem. 40, 347-355.

Ferry, M., Pellizzi, E., Boughattas, I., Fromentin, E., Dauvois, V., Combarieu, G.de, Coignet, P., Cochin, F., Ngono-Ravache, Y., Balanzat, E., Esnouf, S., 2016. Effect of cumulated dose on hydrogen emission from polyethylene irradiated under oxidative atmosphere using gamma rays and ion beams. Radiat. Phys. Chem. 118, 124-127.

Fromm, M., Quinto, A.M., Weck, F.P., Champion, C., 2015. Low energy electrons and swift ion track structure in PADC. Rad. Phis. Chem. 115, 36-42.

Fromm, M., Kodaira, S., Kusumoto, T., Barillon, R., Yamauchi, T., 2019. Role of intermediate species in the formation of ion tracks in PADC: A review. Polym. Degrad. Stab. 161, 213-224.

Fujii, M., Csige, I., Somogyi, G., 1987. The effect of vacuum and UV-exposure on the sensitivity of polymeric track detectors. Proc. $20^{\text {th }}$ Int. Conf. on Cosmic Rays 2, 
414-417.

Fukuda, Y., Faenov, A.Ya., Tampo, M., Pikuz, T.A., Nakamura, T., Kando, M., Hayashi, Y., Yogo, A., Sakaki, H., Kameshima, T., Pirozhkov, A.S. , Ogura, K., Mori, M., Esirkepov, T.Zh., Koga, J., Boldarev, A.S., Gasilov, V.A., Magunov, A.I., Yamauchi, T., Kodama, R., Bolton, P.R., Kato, Y., Tajima, T., Daido, H., Bulanov, S.V., 2009. Energy increase in multi-MeV ion acceleration in the interaction of a short pulse laser with a Cluster-Gas target, Phy. Rev.Lett. 103, 165002.

Fulford, J., Bonner, P., Goodhead, D.T., Hill, M.A., O’Neill, P., 1999. Experimental Determination of the Dependence of $\mathrm{OH}$ Radical Yield on Photon Energy: A Comparison with Theoretical Simulations. J. Phys. Chem. A 103, 11345-11349.

Groetz, J.-E., Ounoghi, N., Mavon, C., Belafrites, A., Fromm, M., 2014. Conception and realization of a parallel-plate free-air ionization chamber for the absolute dosimetry of an ultra soft X-ray beam. Rev. Sci. Instrum. 85, 083304.

Hirano, Y., Kodaira, S., Matsumura, A., Torikoshi, M., 2018. Linear energy transfer (LET) spectra and survival fraction distribution based on the CR-39 plastic charged-particle detector in a spread-out Bragg peak irradiation by a $12 \mathrm{C}$ beam. Phys. Med. Biol. 63, 185006.

Ishigure, N., Nakano, T., Matsuoka, O., 1989. An investigation to assess which component in the air is concerned with the vacuum effect on plastic track detector sensitivity. Nucl. Tracks Radiat Meas. 16, 57-59.

Jahan, M.S., Durant, J., 2005. Investigation of the oxygen-induced radicals in ultra-high molecular weight polyethylene. Nucl. Instrum. Meth. B. 236, 116-172.

Khazal, K.A.R., Habubi, N.F., 1990. ESR induced in CR-39 plastic as a means of gamma ray dosimetry. Isotopenpraxis 26, 237.

Kai, T., Yokoya, A., Uka, M., Fujii, K., Toigawa, T., Watanabe, R., 2018. A significant role of non-thermal equilibrated electrons in the formation of deleterious complex DNA damage. Phys. Chem. Chem. Phys. 20, 2838. 
Kanasaki, M., Jinno, S., Sakaki, H., Kondo, K., Oda, K., Yamauchi, T., Fukuda, Y., 2016. The precise energy spectra measurement of laser-accelerated MeV/n-class high-Z ions and protons using CR-39 detectors, Plasma Physics and Controlled Fusion 58, 034013.

Kodaira, S., Nanjo, D., Kawashima, H., Yasuda, N., Konishi, T., Kurano, M., Kitamura, H., Uchihori, Y., Naka, S., Ota, S., Ideguchi, Y., Hasebe, N., Mori, Y., Yamauchi, T., 2012. Mass spectrometry analysis of etch products from CR-39 plastic irradiated by heavy ions. Nucl. Instrum. Meth. B. 286, 229-232.

Hirano, Y., Kodaira, S., Souda, H., Matsumura, A., Torikoshi, M., 2018. Linear energy transfer (LET) spectra and survival fraction distribution based on the CR-39 plastic charged-particle detector in a spread-out Bragg peak irradiation by a ${ }^{12} \mathrm{C}$ beam. Phys. Med. Biol. 63, 185006.

Kiselev, S.I., Khmelenko, V.V., Bernard, E.P., Lee, D.M., 2003. ESR investigation of hydrogen and deuterium atoms in impurity-helium solids. Low Temp. Phys. 29(6), 505-509.

Kusumoto, T., Mori, Y., Kanasaki, M., Ueno, T., Kameda, Y., Oda, K., Kodaira, S., Kitamura, H., Barillon, R., Yamauchi, T., 2015. Yields on the formation of OH groups and the loss of $\mathrm{CH}$ groups along nuclear tracks in PADC films. Radiat. Meas. 83, 59-62.

Kusumoto, T., Mori, Y., Kanasaki, M., Ikenaga, R., Oda, K., Kodaira, S., Kitamura, H., Barillon, R., Yamauchi, T., 2016a. Radiation chemical yields for the losses of typical functional groups in PADC films for high energy protons registered as unetchable tracks. Radiat. Meas. 87, 35-42.

Kusumoto, T., Mori, Y., Kanasaki, M., Oda, K., Kodaira, S., Honda, Y., Tojo, S., Barillon, R., Yamauchi, T., 2016b. Sudden increase of the radiation chemical yield for loss of carbonate ester in PADC detector where the track overlapping of $28 \mathrm{MeV}$ electrons becomes significant. JPS. Conf. Proc. 11, 010001.

Kusumoto, T., Fromm, M., Cloutier, P., Bass, A.D., Sanche, L., Barillon R., Yamauchi, T., 2018 Elucidation of the Two-Step Damage Formation Process of Latent Tracks in Poly(allyl diglycol carbonate), PADC: Role of Secondary Low-Energy Electrons. J. 
Phys. Chem. C 122, 21056-21061.

Kusumoto, T., Ngono-Ravache, Y., Balanzat, E., Galindo, C., Ludwig, N., Raffy, Q., Yamauchi, T., Kodaira, S., Barillon, R., 2019a. The role of molecular and radical mobility in the creation of $\mathrm{CO}_{2}$ molecules and $\mathrm{OH}$ groups in PADC irradiated with $\mathrm{C}$ and O ions. Poly. Degrad. Stab. 164, 102-108.

Kusumoto, T., Mori, Y., Kanasaki, M., Oda, K., Kodaira, S., Barillon, R., Yamauchi, T., 2019b. Drastic decrease of carbonyl group after the loss of ether in PADC exposed to 222 nm UV photons. Radiat. Phys. Chem. 157, 60-64.

Lounis-Mokrani, Z., Fromm, M., Barillon, R., Chambaudet, A., Allab, M., Characterization of chemical and optical modifications induced by $22.5 \mathrm{MeV}$ proton beams in CR-39 detectors. Radiat. Meas. 36, 615-620.

Mori, Y., Ikeda, T., Yamauchi, T., Sakamoto, A., Chikada, H., Honda, Y., Oda, K., 2009. Radiation chemical yield for loss of carbonate ester bonds in PADC films exposed to gamma ray. Radiat. Meas. 44, 211-213.

Mori, Y., Yamauchi, T., Kanasaki, M., Maeda, Y., Oda, K., Kodaira, S., Konishi, T., Yasuda, N., Barillon, R., 2011. Radiation chemical yields for loss of ether and carbonate ester bonds in PADC films exposed to proton and heavy ion beams. Radiat. Meas. 46, 1147-1153.

Mori, Y., Yamauchi, T., Kanasaki, M., Hattori, A., Matai, Y., Matukawa, K., Oda, K., Kodaira, S., Kitamura, H., Konishi, T., Yasuda, N., Tojo, S., Honda, Y., Barillon, R., 2012. Greater radiation chemical yields for losses of ether and carbonate ester bonds at lower stopping powers along heavy ion tracks in poly(allyl diglycol carbonate) films. Appl. Phys. Express 5, 086401.

Mori, Y., Yamauchi, T., Kanasaki, M., Hattori, A., Oda, K., Kodaira, S., Konishi, T., Yasuda, N., Tojo, S., Honda, Y., Barillon, R., 2013. Vacuum effects on the radiation chemical yields in PADC films exposed to gamma rays and heavy ions. Radiat. Meas. 50, 97-102.

Nakashima, K., Yamauchi, J., 2005. ESR Investigation of a Stable Trapped Hydrogen 
Atom in X-ray-Irradiated $\beta$-Tricalcium Phosphate at Room Temperature. J. Am. Chem. Soc. 127(6), 1606-1607.

Neta, P., Schuler, R.H., 1971. Rate Constants for Reaction of Hydrogen Atoms with Compounds of Biochemical Interest. Radiat. Res. 47, 612-627.

Oda, K., Yoshida, K., Yamauchi, T., 1997. Effects of low-LET radiations on CR-39 track detector. Radiat. Meas. 28, 85-88.

Oganesyan, V.R., Trofimov, V.V., Gaillard, S., Fromm, M., Danziger, M., Hermsdorf, D., Orelovitch, O.L., 2005. Investigation of the response of thin CR-39 polymer foils irradiated with light ions. Nucl. Instrum. Meth. B, 236, 289-294.

Okada, S., Murakami, K., Incerti, S., Amako, K., Sasaki, T., 2019. MPEX-DNA, a new GPU-based Monte Carlo simulator for track structures and radiation chemistry at subcellular scale. Med. Phys. 46(3), 1483-1500.

Ounoughi, N., Mavon, C., Belafrites, A., Groetz, J.-E., Fromm, M., 2013. Beam characterization of a lab bench cold cathode ultra-soft X-ray generator. Nucl Instrum. Meth. B 305, 61-66.

Petersen, F., Enge, W., 1995. Energy loss dependent transversal etching rates of heavy ion tracks in plastic. Radiat. Meas. 25, 43-46.

Ranjbar, A.H., Durrani, S.A., Randle, D.K., 1997. Investigations of the use of electron sping resonace for nuclear track counting and gamma-ray dosimetry in CR-39. Radiat. Meas. 28, 831-834.

Rowntree, P., Parenteau, L., Sanche, L., 1991. Anion yields produced by low-energy electron impact on condensed hydrocarbon films. J. Phys. Chem. 95, 4902-4909.

Sato, T., Iwamoto, Y., Hashimoto, S., Ogawa, T., Furuta, T., Abe, S., Kai, T., Tsai, P.E., Matsuda, N., Iwase, H., Shigyo, N., Sihver, L., Nitta, K., 2018. Features of Particle and Heavy Ion Transport Code System PHITS version 3.02, J. Nucl. Sci. Technol. 55, 684-690. 
Seah, M.P., Dench, W.A., 1979. Quantitative electron spectroscopy of surfaces: A standard data base for electron inelastic mean free paths in solids. Surf. Interface Anal. 1, $2-11$.

Sevilla, M.D., Summerfield, S., Eliezer, I., Rak, J., Symons,M.C.R., 1999. Interaction of the Chlorine Atom with Water: ESR and ab Initio MO Evidence for Three-Electron $\left(\sigma^{2} \sigma^{* 1}\right)$ Bonding. J. Phys. Chem. A 101. 2910-2915.

Shiryaeva, E.S., Sosulin, I.S., Saenko, E.V., Feldman, V.I., 2016. Ion-radical intermediates of the radiation-chemical transformations of organic carbonates. Radiat. Phys. Chem. 124, 19-25.

Stejny, J., 1987. The polymer physics of CR-39 - The state of understanding. Radiat. Prot. Dosim. 20, 31-36.

Stößer, R., Herrmann, W., 2013. Isotope Effects in ESR Spectroscopy. Molecules 18, 6679-6722.

Sun, Y., Zhu, Z., Wang, Z., Liu, J., Jin, Y., Hou, M., Wang, Y., Duan, J., 2003a. The damage process induced by swift heavy ion in polycarbonate. Nucl Instrum. Meth. B 212, 211-215.

Sun, Y., Zhu, A., Wang, Z., Jin, Y., Liu, J., Hou, M., Zhang, Q., 2003b. Swift heavy ion induced amorphization and chemical modification in polycarbonate. Nucl. Instrum. Meth. B 209, 188-193.

Swarts, S.T., Becker, D., DeBolt, S., Sevilla, M.D., 1989. An Electron Spin Resonance Investigation of the Structure and Formation of Sulfinyl Radicals: Reaction of Peroxyl Radicals with Thiols. J. Phys. Chem. 93, 155-161.

Yamauchi, T., Oda, K., Miyake, H., 1992. An evaluation of the radial life-time in CR-39 track detectors outgassed under vacuum. Nucl. Tracks Radiat. Meas. 20, 615-617.

Yamauchi, T., Taniguchi, T., Oda, K., 1999. Study on response of CR-39 detector to light ions. Radiat. Meas. 31, 261-264. 
Yamauchi, T., 2003. Studies on the nuclear tracks in CR-39 plastics. Radiat. Meas. 36, 73-81.

Yamauchi, T., Barillon, R., Balanzat, E., Asuka, T., Izumi, K., Masutani, T., Oda, K., 2005. Yields of $\mathrm{CO}_{2}$ formation and scissions at ether bonds along nuclear tracks in CR-39. Radiat. Meas. 40, 224-228.

Yamauchi, T., Yasuda, N., Asuka, T., Izumi, K., Masutani, T., Oda, K., Barillon, R., 2005b. Track core size estimation for heavy ions in CR-39 by AFM and UV methods. Nucl. Instrum. Meth. B 236, 318-322.

Yamauchi, T., Watanabe, S., Seto,A. ,Oda, K., Yasuda,N., Barillon,R., 2008. Loss of carbonate ester bonds along Fe ion tracks in thin CR-39 films. Radiat. Meas. 43, S106-S110.

Yamauchi, T., Mori, Y., Oda, K., Kodaira, S., Yasuda, N., Barillon, R., 2010. On the tracks of proton and heavy ions in PC and PADC plastics detectors. In: Proceedings of the $24^{\text {th }}$ Workshop on Radiation Detector and Their Uses. KEK Proceedings, Tsukuba, Japan, 10, 1-11. 


\section{Figure captions}

Fig. 1 A repeat unit of PADC.

Fig. 2 Layered structure in PADC after irradiation with 4.8 MeV/u C ions.

Fig. 3 IR spectra before (dotted red line) and after (solid blue line) exposure to Co-60 gamma rays. In the panels (a), (c), (e) and (g), the evolutions of spectra after the exposure with absorbed dose of $60 \mathrm{kGy}$ is shown. Additionally, the evolutions after the exposure with $300 \mathrm{kGy}$ are shown in the panels (b), (d), (f) and (h) (Mori et al., 2009).

Fig. 4 ESR spectra measured at $77 \mathrm{~K}$. The full red, dotted black and chain green lines describe the spectra after exposure to Co-60 gamma rays at $77 \mathrm{~K}$ with absorbed doses of 33 (below the critical dose), 67 (around the critical dose) and $100 \mathrm{kGy}$ (above the critical dose), respectively.

Fig. 5 ESR spectra measured at RT. The full red and chain green lines describe the spectra after exposure to gamma ray at RT with absorbed doses of 33 (below the critical dose) and $100 \mathrm{kGy}$ (above the critical dose), respectively.

Fig. 6 The relative absorbance of typical functional groups in PADC after the 
exposures to Co-60 gamma rays (a) and USX (b) at RT. The open symbols in Fig. 2 (a) indicates the previous results (Mori et al., 2009). The reduction trend of relative absorbance after in a wide dose range is represented in the inset of Fig. 6(a).

Fig. 7 Summary of $G$ values for losses of ether in PADC. The present results of gamma ray and USX are plotted as solid squares. The $\mathrm{G}$ values of proton, heavy ions with energies around Bragg Peak are plotted as open circles (Mori et al., 2009) and those of high energy protons $(20,30$ and $70 \mathrm{MeV})$ and semi-relativistic heavy ions of $\mathrm{C}$ and $\mathrm{Fe}(>100 \mathrm{MeV} / \mathrm{u}$ ) are shown as open diamonds (Kusumoto et al., 2016a; Mori et al., 2012). The previously obtained $\mathrm{G}$ values of gamma ray and $28 \mathrm{MeV}$ electrons are also described as open triangles (Mori et al., 2009; Kusumoto et al., 2016b).

Fig. 8 Summary of $\mathrm{G}$ values for losses of carbonate ester in PADC. The present results of Co-60 gamma rays and USX are plotted as solid squares. The G values of proton, heavy ions with energies around Bragg Peak are plotted as open circles (Mori et al., 2009) and those of high energy protons (20, 30 and $70 \mathrm{MeV}$ ) and semi-relativistic heavy ions of $\mathrm{C}$ and $\mathrm{Fe}(>100 \mathrm{MeV} / \mathrm{u}$ ) are shown as open diamonds (Kusumoto et al., 2016a; Mori et al., 2012). The previously obtained $\mathrm{G}$ values of gamma ray and $28 \mathrm{MeV}$ electrons are also described as open triangles (Mori et al., 2009; Kusumoto et al., 2016b). 
Fig. 1<smiles>CCCC(C)COC(=O)OCCOCCOC(=O)OCC(C)CC</smiles> 
Fig. 2

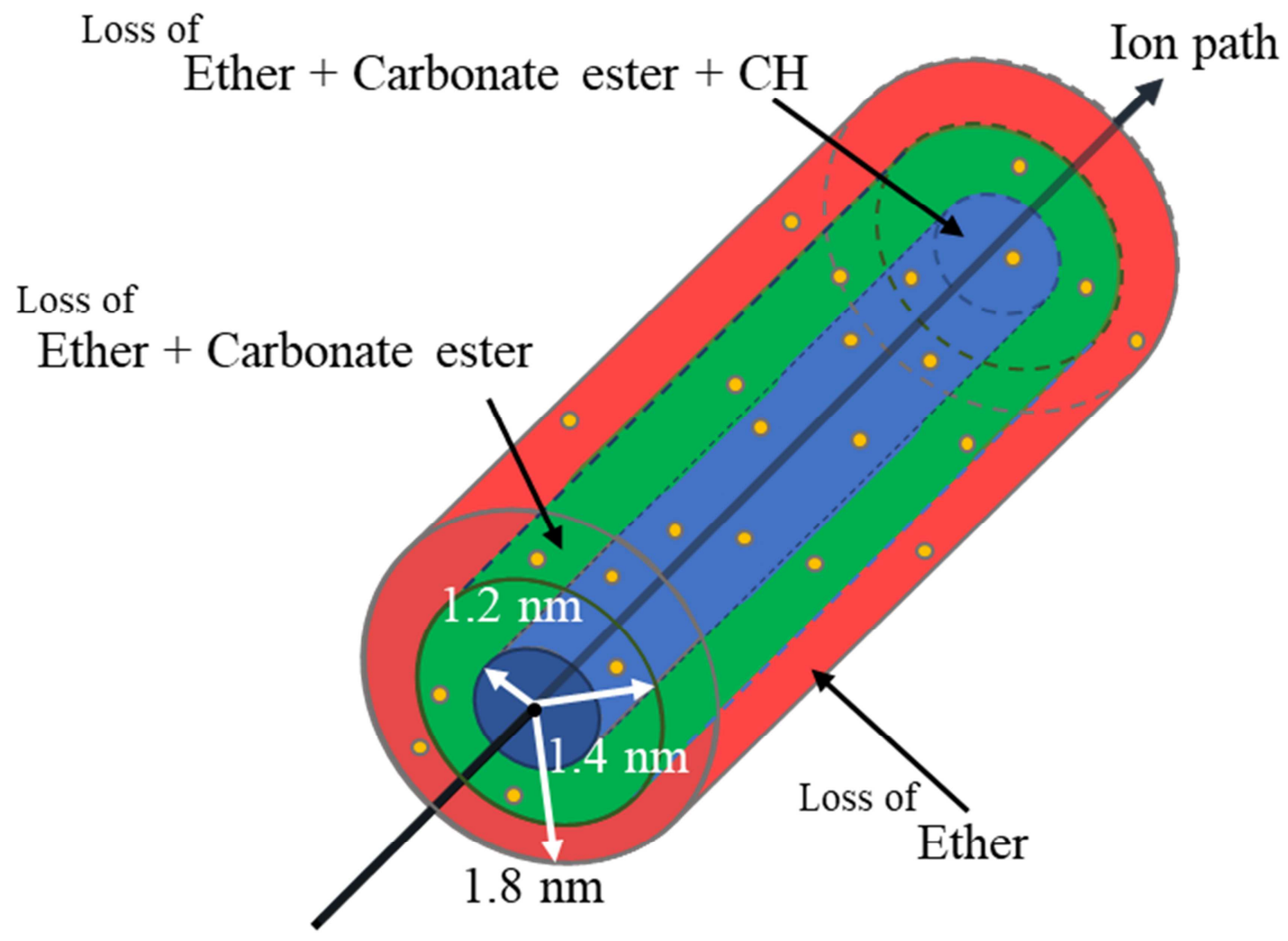


Fig. 3

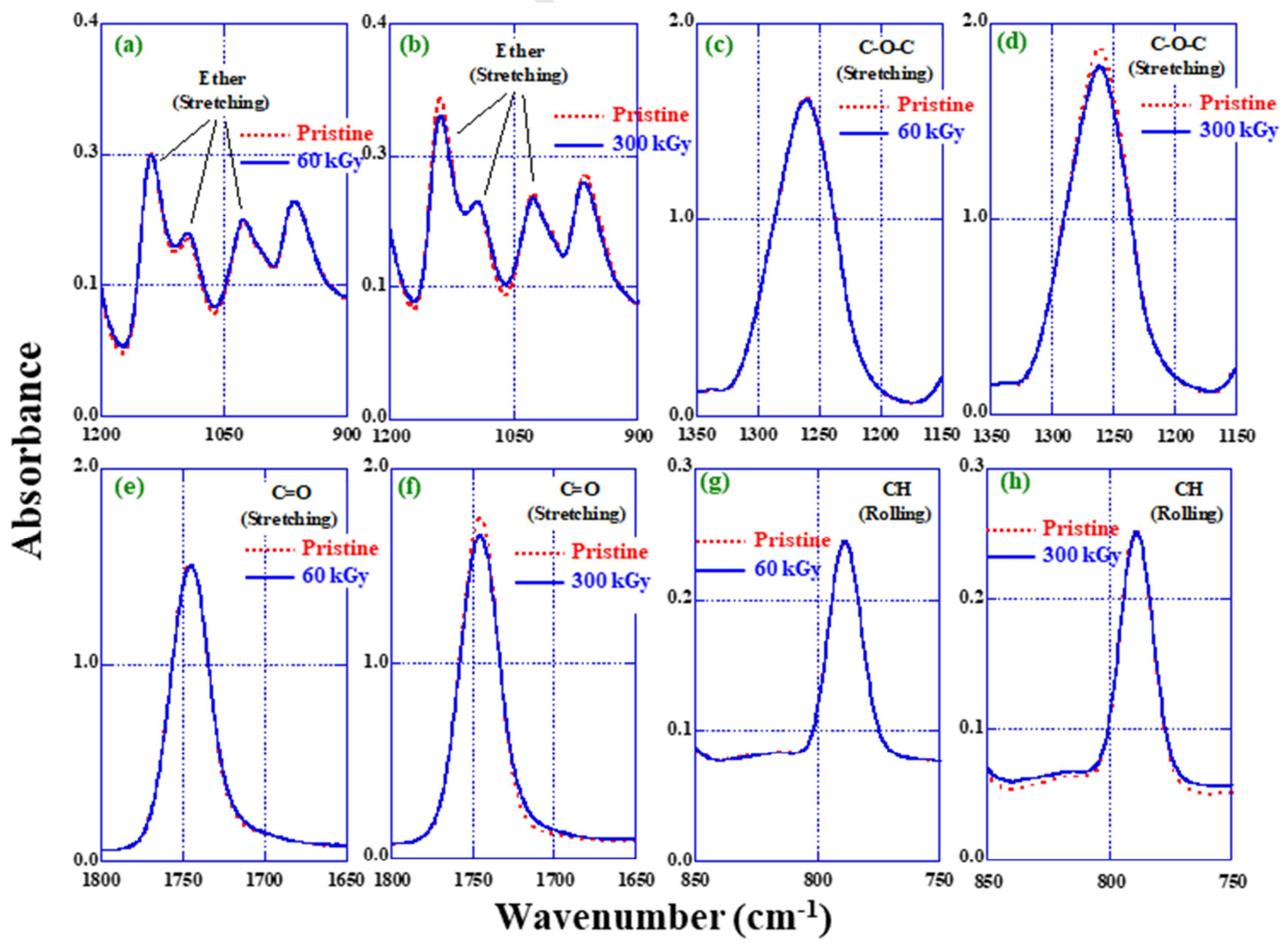


Fig .4

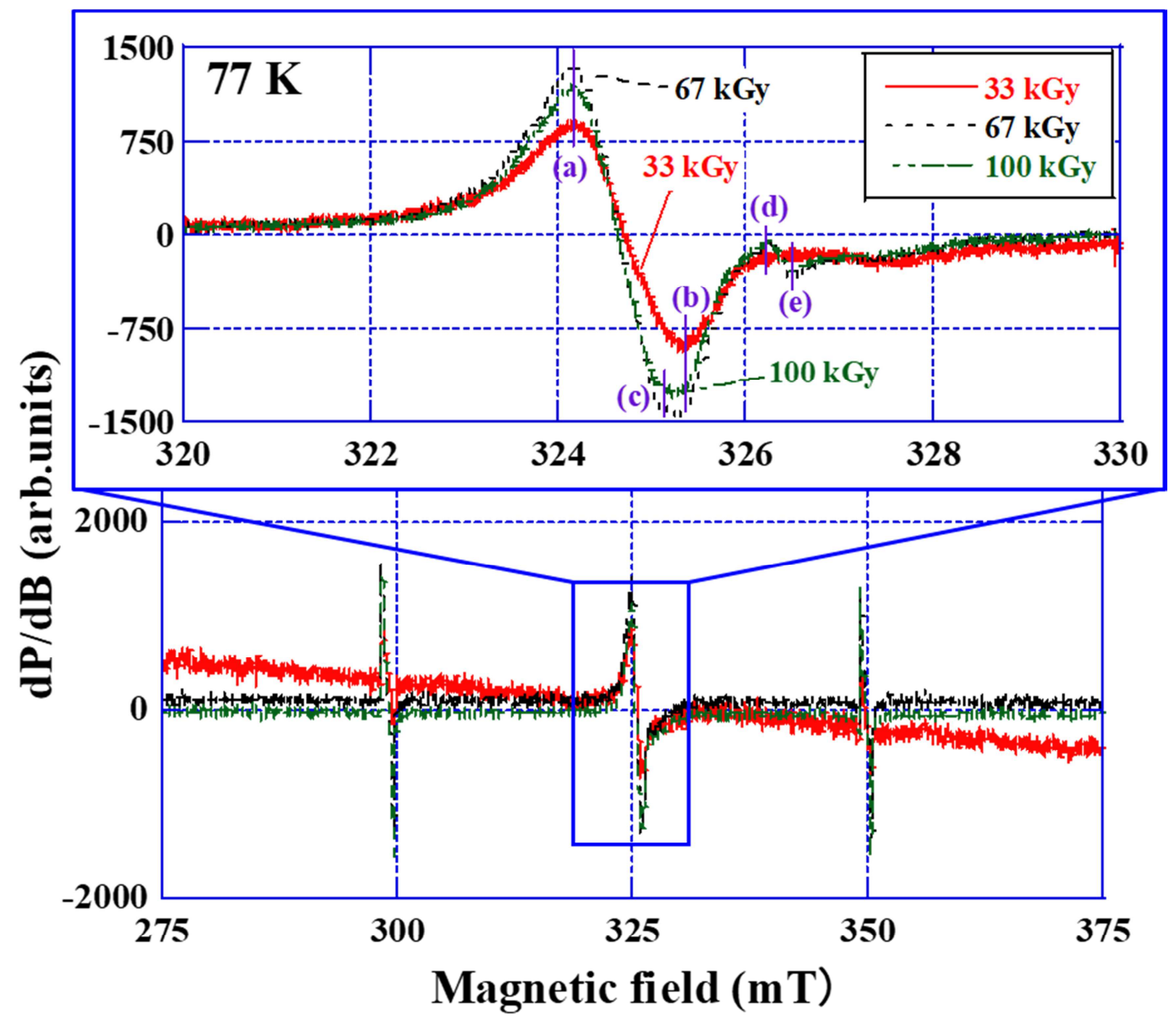




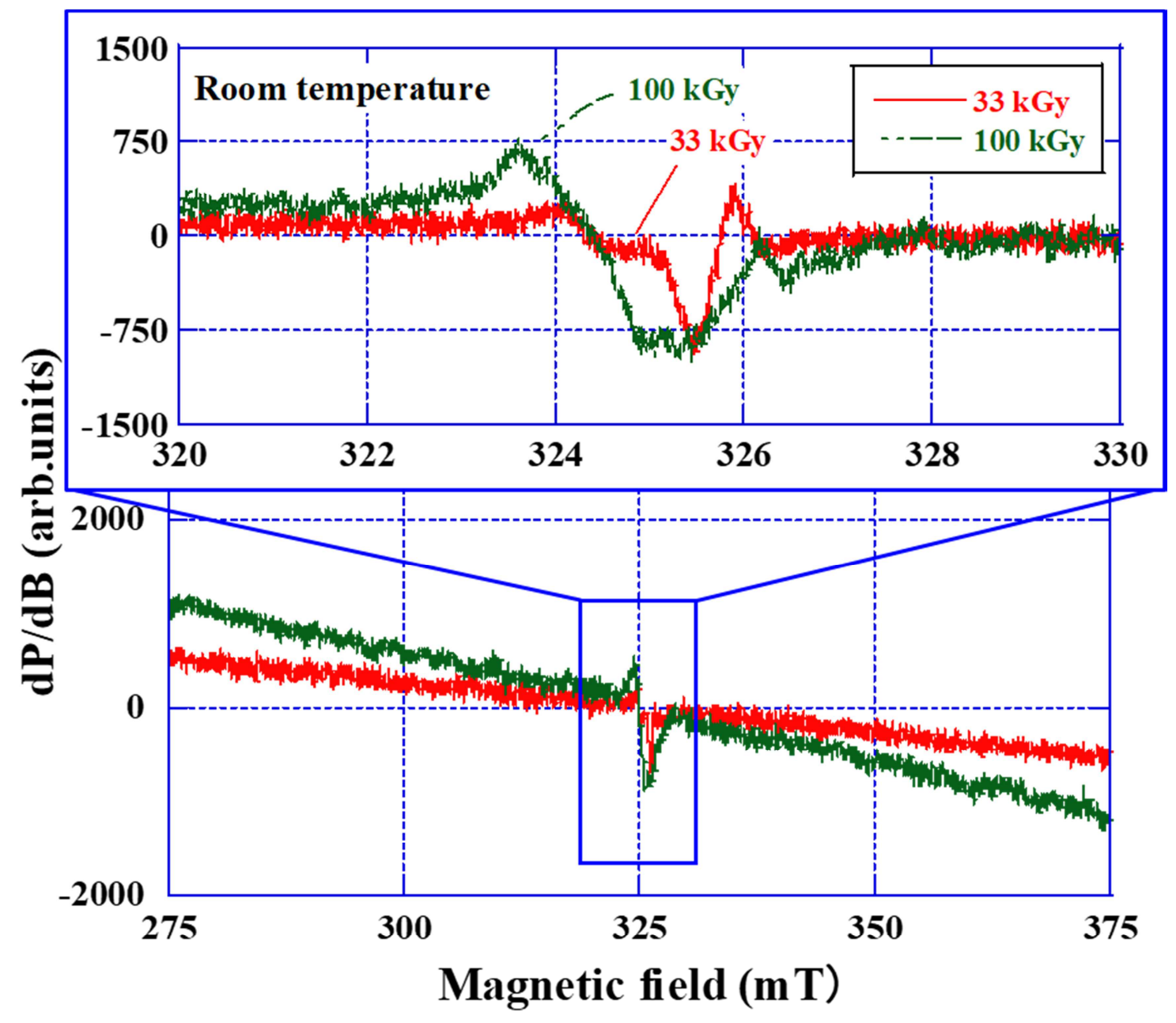

Fig. 5 
Fig. 6 (a)

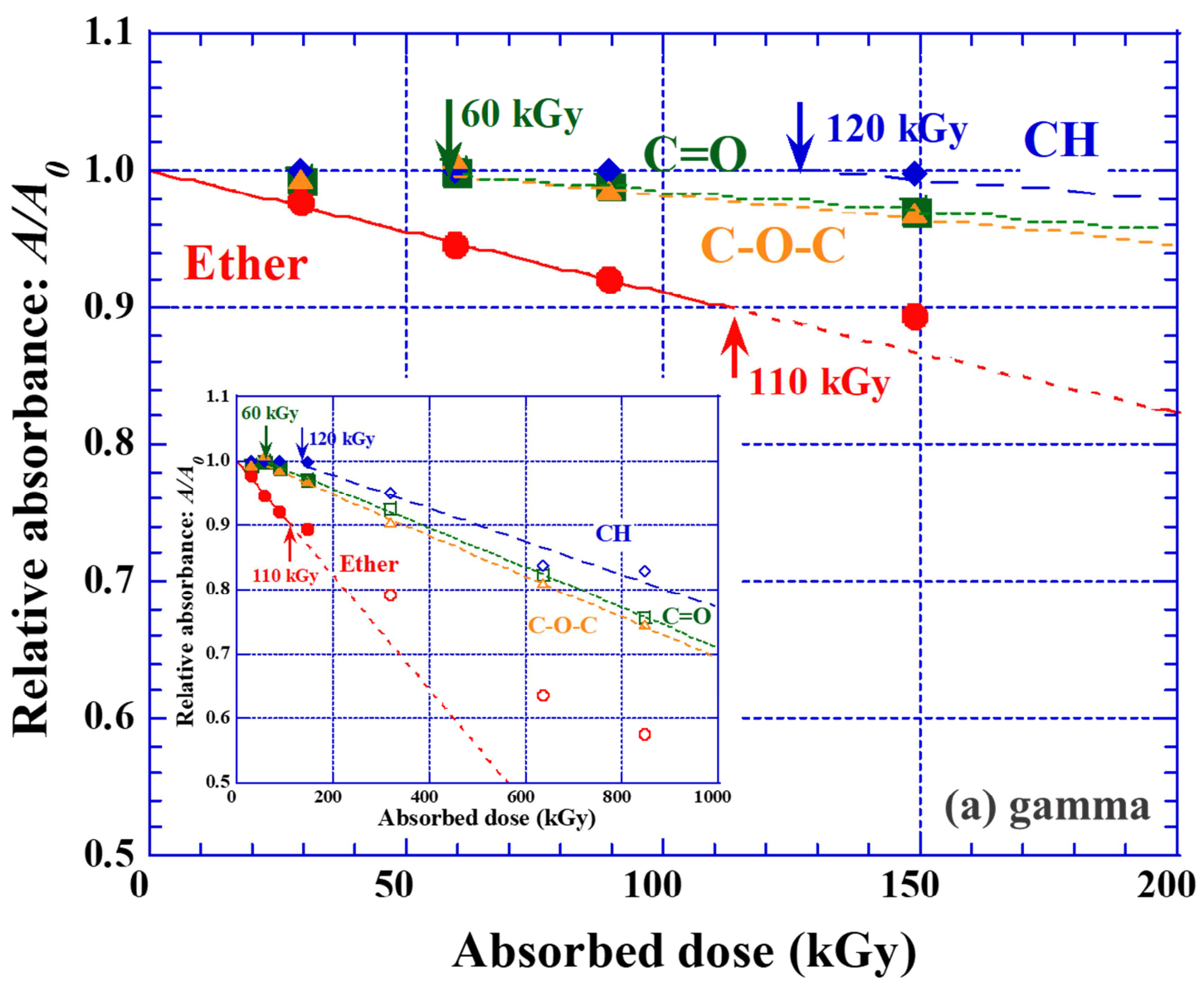


Fig. 6 (b)

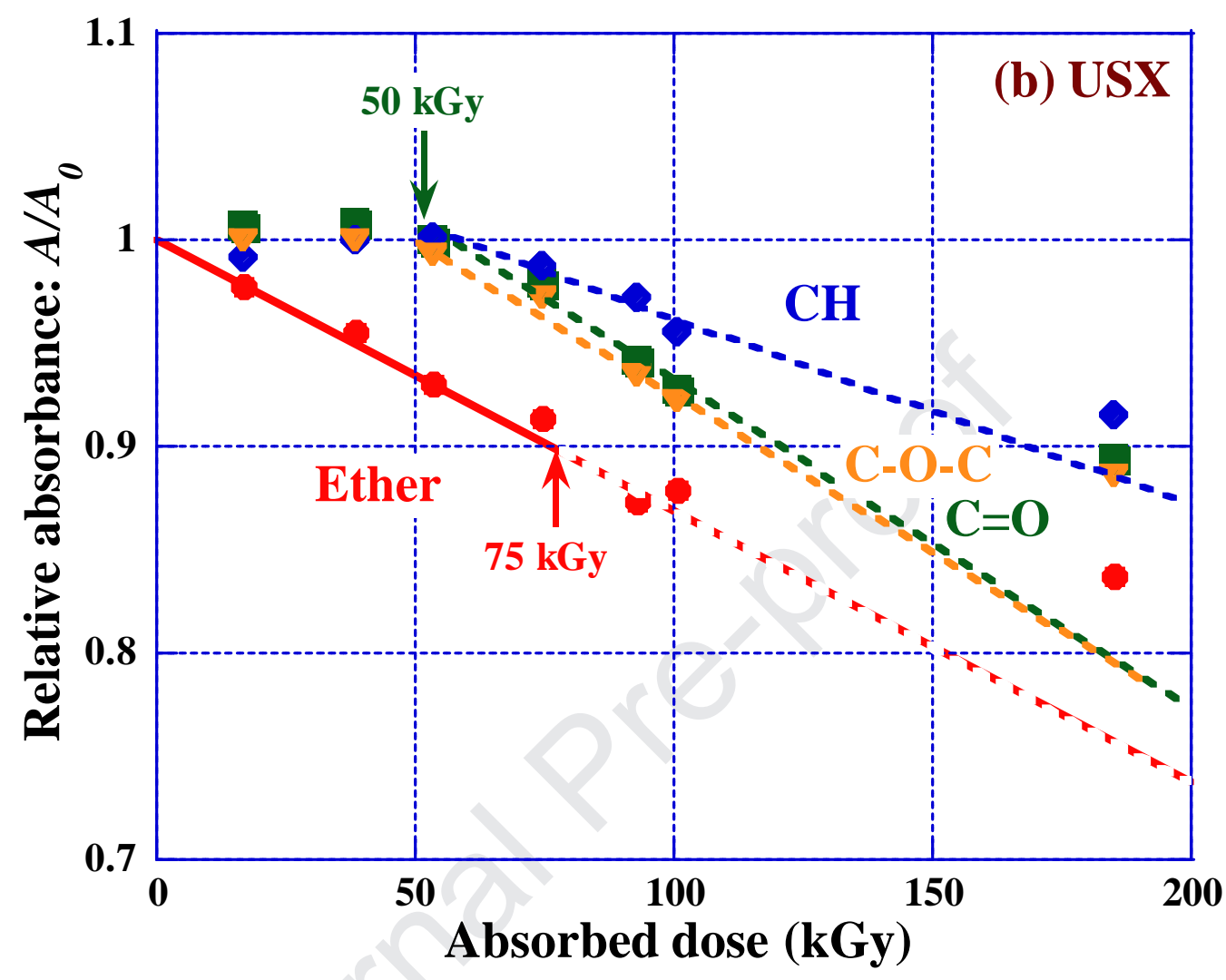


Fig. 7

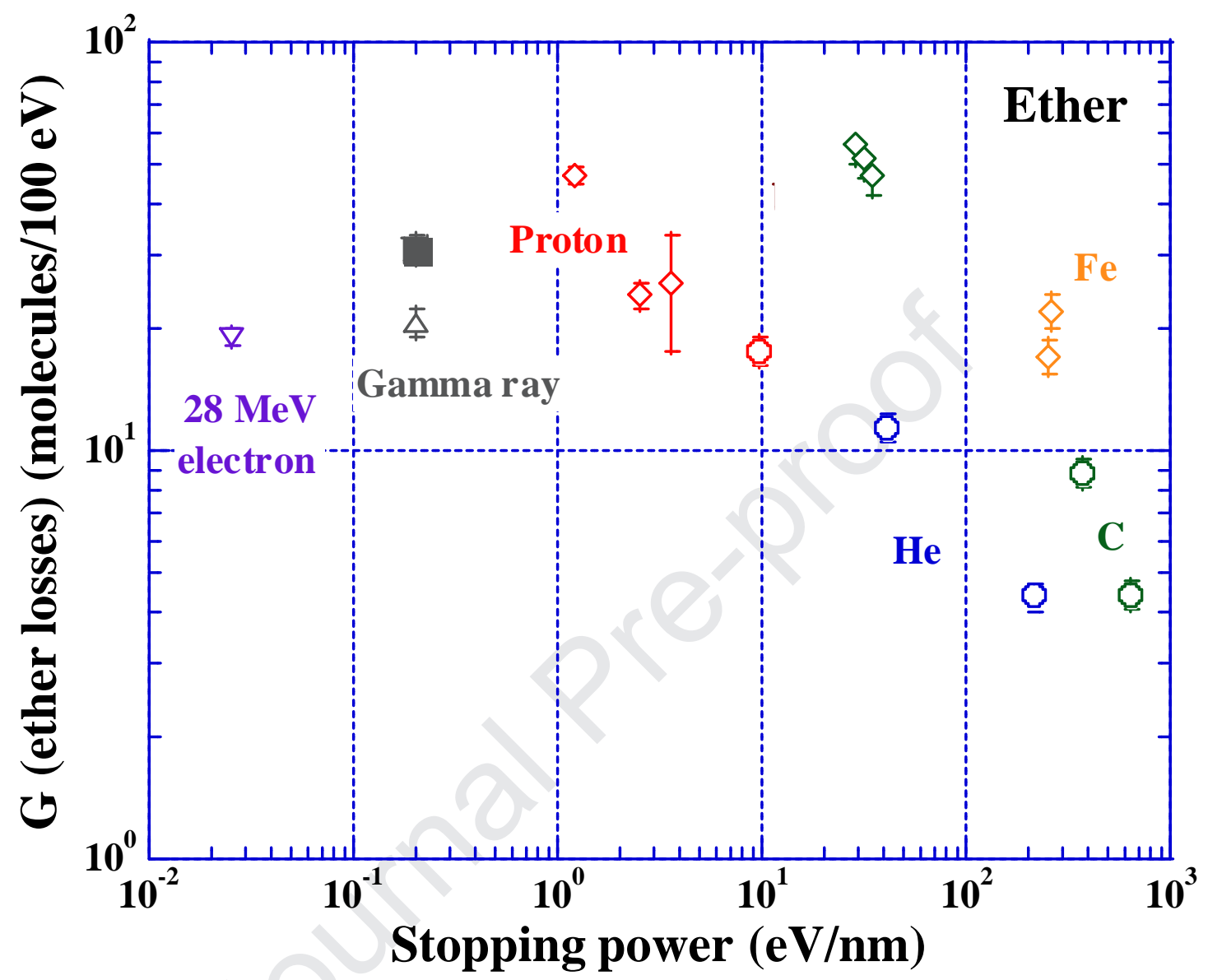


Fig. 8

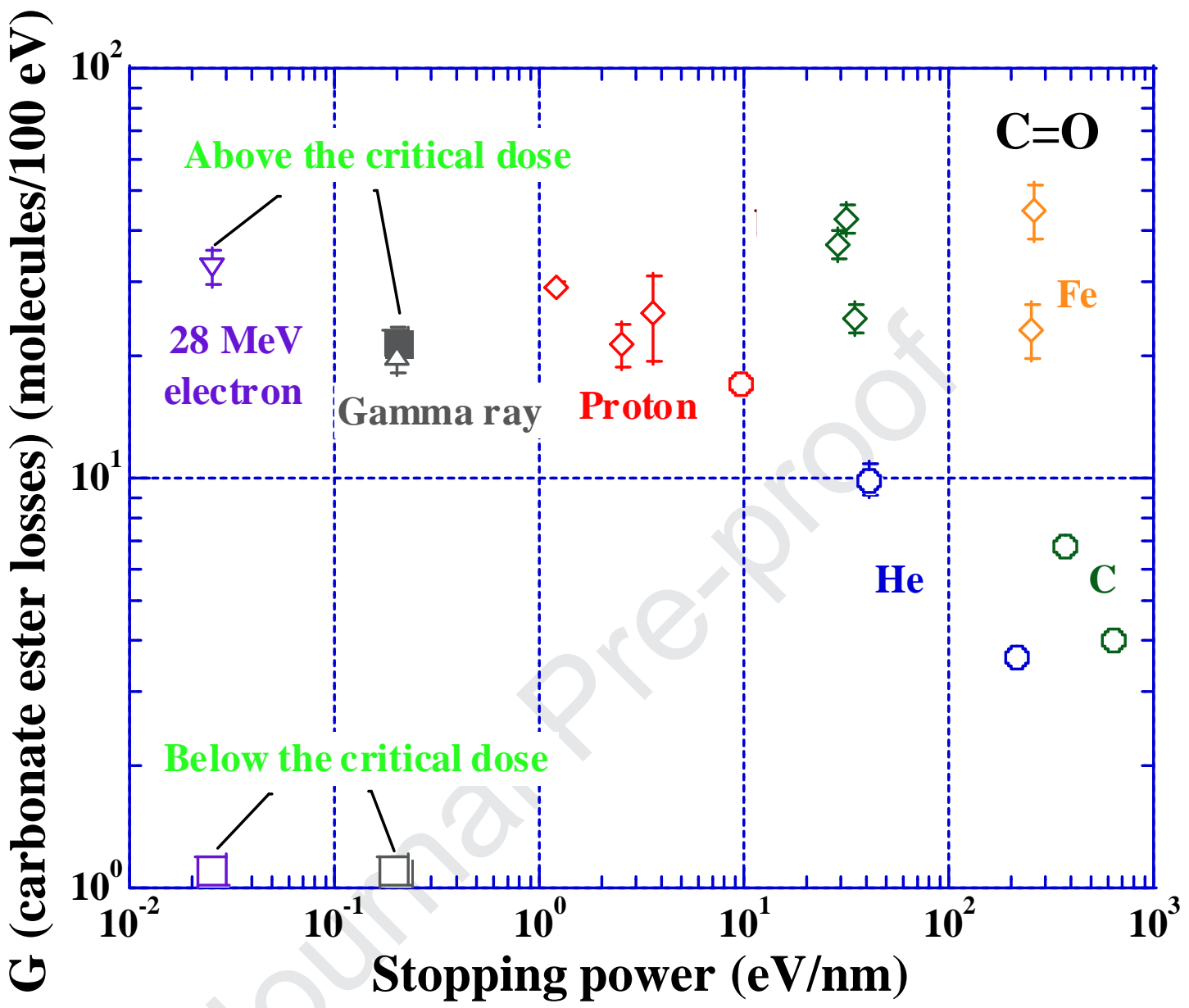


Highlights

A significant different ESR signals is observed at both sides of a critical dose.

The density of carbonate ester in PADC begins decreasing above a critical dose.

Number of electrons and their energies are important for mechanism of latent tracks. 
Conflict of Interest

We have no interesting to confliction. 